\title{
ТЕПЛОПЕРЕНОС В МАЛОМ ПО ТОЛЩИНЕ СЛОЕ ЖИДКОСТИ В УСЛОВИЯХ, ХАРАКТЕРНЫХ ДЛЯ НИЖНЕЙ КРЫШКИ ТЕРМОСИФОНА
}

\author{
Феоктистов Дмитрий Владимирович', \\ fdv@tpu.ru
}

\author{
Пономарев Константин Олегович1, \\ kop.tpu@gmail.com \\ 1 Национальный исследовательский Томский политехнический университет, \\ Россия, 634050, г. Томск, пр. Ленина, 30.
}

\begin{abstract}
Актуальность. Создание новых технологий утилизации теплоты дымовых газов, образующихся в различных металлургических процессах и при сжигании органических топлив на тепловых электростанциях, невозможно без развития фундаментальных знаний процессов теплопереноса в энергоэфффективных надежных термодинамических системах на базе термосифонов. Актуальность исследования процессов теплопереноса в относительно тонком (толщиной не более 10 мм) слое теплоносителя в испарителе термосифона обоснована необходимостью разработки математических моделей более простых по сравнению с моделями на базе уравнений Навье-Стокса, или учитывающих только механизм теплопроводности.

Цель: оценка вклада термогравитационной конвекции в процесс теплопереноса в малом по толщине слое жидкости в условиях, характерных для нижней крышки термосифона - при нагреве нижней поверхности слоя и испарении его с верхней поверхности.

Методы. Теневым методом установлены траектории трассеров в слое жидкости. Регистрация перемещений трассеров проводилась Particle Tracking Velocimetry методом с использованием специальной системы визуализации. Задача теплопроводности в слое жидкости решена методом конечных разностей.

Результаты. По результатам экспериментальных исследований теплопереноса в слое жидкости малой толщины в условиях, соответствующих по основным значимым фракторам нагреву теплоносителя на нижней крышке термосифона, установлено влияние плотности теплового потока, толщины слоя жидкости, свойств теплоносителя на температуры и скорости в этом слое. Установлено, что увеличение теплового потока и рост толщины слоя теплоносителя приводят к интенсифи-

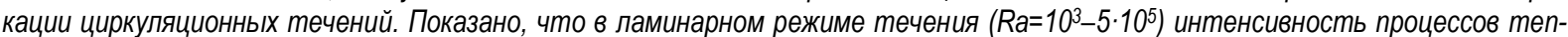
лопереноса в слое этанола выше, чем в воде. Установлено, что в малом по толщине слое жидкости (от 3,2 до 7,4 мм) процесс термогравитационной конвекции интенсивнее процесса теплопроводности.
\end{abstract}

\section{Ключевые слова:}

Термосифон, слой жидкости, термогравитационная конвекция, эксперимент, скорость движения жидкости, тепловой поток.

\section{Введение}

Использование систем на базе термосифонов для регенерации теплоты дымовых газов, образующихся в различных металлургических процессах и при сжигании органических топлив на тепловых электростанциях, является перспективным техническим решением, приводящим к повышению энергоэффективности, эксплуатационной надежности всей конструкции $[1,2]$. Термосифоны обладают рядом преимуществ (простота, высокие теплопередающие характеристики, возможность использования большого числа различных теплоносителей, отсутствие дополнительных перекачивающих средств) [1], что делает их эффективными теплообменниками, широко применяющимися для отвода теплоты от систем выработки энергии. Но широкое внедрение термосифонов до последнего времени сдерживается в связи с отсутствием системы фундаментальных знаний (результатов экспериментов, физических и математических моделей, методов решения задач, теоретических следствий), необходимых для создания систем утилизации теплоты дымовых газов многих производств. Результаты известных экспериментов (например, [2-4]) недостаточны для проведения опытно-конструкторских работ по устройствам разного рода на базе термосифонов. Основные математические модели теплопереноса в тер- мосифонах (например, [5, 6]), описывающие теплофизические и гидродинамические процессы во всех зонах и рабочих трактах термосифонов, слишком громоздки и сложны при решении инженерных задач. Поэтому актуальным является создание существенно менее сложных моделей, обеспечивающих возможность адекватного прогнозирования рабочих характеристик термосифонов. Одним из вариантов моделирования является описание процессов теплопереноса только в зоне испарения на нижней крышке термосифона, но с вычислением скорости парообразования, зная которую можно адекватно рассчитать все рабочие характеристики термосифона. Известны математические модели (например, [7]), в которых предполагается, что теплоперенос в слое жидкого теплоносителя в испарителе термосифона (рис. 1, а) осуществляется только за счет теплопроводности. В то же время оценки перепадов температуры по этому слою в типичных [8] режимах работы термосифонов показывают высокую вероятность реализации при подводе теплоты к нижней поверхности этого относительно тонкого слоя теплоносителя режима термогравитационной конвекции. Результаты экспериментальных исследований гидродинамических процессов в слое жидкого теплоносителя в испарителе термосифона пока не опубликованы. Поэтому целесообразно 
проведение экспериментальных исследований по определению скоростей термогравитационной конвекции в слое жидкости в условиях, характерных для термосифона. Такие экспериментальные данные необходимы для разработки математических моделей более простых, по сравнению с моделями на базе системы нестационарных уравнений Навье-Стокса [9].

В дополнение к вышеизложенному необходимо отметить, что актуальность исследования процессов теплопереноса в относительно тонком (толщиной не более 10 мм) слое жидкости в условиях термогравитационной конвекции подтверждается многочисленными техническими приложениями $[10,11]$ и ростом публикаций по этой тематике в последние годы (например, $[12,137)$. Интерес к тематике вызван усовершенствованием численных методов решения нелинейных уравнений гидродинамики и переноса теплоты в слое теплоносителя. Определение скоростей конвективных течений в горизонтальном слое жидкости при интенсивном нагреве нижней поверхности и испарении с верхней поверхности слоя является примером фундаментальной задачи теплофизики. Экспериментально конвективные структуры изучались преимущественно с помощью PIV-метода [14] или трехмерных томографических измерений [15]. В экспериментальных исследованиях [16] использовался метод «трассерной» визуализации Particle Tracking Velocimetry (PTV). Этот метод применяется при регистрации движения частиц или объектов малых размеров [17] и определении профиля мгновенных скоростей [18]. Известны результаты экспериментальных $[15,19]$ и численных $[20,21]$ исследований, в которых испарение с поверхности горизонтального слоя жидкости происходило без нагрева при комнатной температуре, но в условиях движения инертного газа над слоем жидкости. Изучено [22] влияние температуры слоя жидкости и скорости потока газа, движущегося параллельно свободной поверхности, на структуру и скорости конвективных течений в слое. Из-за движения инертного газа возникает градиент температуры вдоль поверхности раздела «жидкость-газ», что приводит к нестабильности поверхности (конвекции Марангони) $[15,19,22]$. В термосифонах, в отличие от условий, которые рассматривались в [15, 19, 22], газ над свободной поверхностью теплоносителя в испарителе не движется параллельно поверхности раздела «жидкость-газ». Поэтому можно предположить, что термокапиллярная конвекция играет меньшую роль, по сравнению с термогравитационной конвекцией.

Стоит отметить, что при нагревании одной из вертикальных поверхностей слоя жидкости [23, 24] влияние термокапиллярного эффекта на температуры и скорости в слое будет существенным. Согласно выводам [25] в слое воды и этанола со свободной поверхностью при температурах, близких к комнатным, термокапиллярный эффект не проявляется и конвекция имеет термогравитационную природу. На основании выше сказанного можно сделать вывод, что в слое жидкости на нижней крышке термосифона, подвод теплоты к которому осуществляется только с нижней стороны, конвекция имеет термогравитационную природу.
Целью работы являлась оценка вклада термогравитационной конвекции в процесс теплопереноса в малом по толщине слое жидкости в условиях, характерных для нижней крышки термосифона - при нагреве нижней поверхности слоя и испарении с его верхней поверхности.

\section{Методика экспериментального исследования}

Условие установки термосифона непосредственно на теплонагруженную поверхность энергонасыщенного оборудования соответствует задаче прикладного характера. В табл. 1 приведены примеры технологического оборудования с плоской горизонтально ориентированной теплонагруженной поверхностью, которую необходимо охлаждать до регламентированных значений температур. От таких поверхностей подвод теплоты в испаритель термосифона происходит только с нижней стенки.

Таблица 1. Температуры поверхностей при номинальных и аварийных режимах работы теплового технологического оборудования

Table 1. Surface temperatures at nominal and emergency operating modes of thermal technological equipment

\begin{tabular}{|c|c|}
\hline $\begin{array}{l}\text { Отрасль } \\
\text { промыш- } \\
\text { ленности } \\
\text { Industry }\end{array}$ & $\begin{array}{c}\text { Температуры поверхностей при номинальных и } \\
\text { аварийных режимах работы теплового технологи- } \\
\text { ческого оборудования } \\
\text { Surface temperatures at nominal and emergency operat- } \\
\text { ing modes of thermal technological equipment }\end{array}$ \\
\hline $\begin{array}{l}\text { Ядерная } \\
\text { Nuclear }\end{array}$ & $\begin{array}{l}\text { Максимально допустимые температуры поверхностей } \\
\text { Махіmum permissible surface temperatures: } \\
\text { Шкафа электронного оборудования } \\
\text { Сabinet of electronic equipment }\left(T_{\text {heater }}=60{ }^{\circ} \mathrm{C}\right)[26] \\
\text { Пластинчатого твэла низкоэнергетических реакторов } \\
\text { Plate fuel element for low-energy reactors } \\
\left(T_{\text {heater }}=100^{\circ} \mathrm{C}\right)[27]\end{array}$ \\
\hline $\begin{array}{l}\text { Металлур- } \\
\text { гическая } \\
\text { Metallurgical }\end{array}$ & $\begin{array}{l}\text { Характерные температуры поверхности машин не- } \\
\text { прерывного литья заготовок/Typical surface } \\
\text { temperature of continuous casting machines } \\
\left(T_{\text {heater }}=85^{\circ} \mathrm{C}\right)[28]\end{array}$ \\
\hline $\begin{array}{l}\text { Энергетиче- } \\
\text { ская } \\
\text { Energy }\end{array}$ & $\begin{array}{l}\text { Максимально допустимые температуры поверхно- } \\
\text { стей } \\
\text { Махіmum permissible surface temperatures: } \\
\text { Аккумуляторных батарей } \\
\text { Accumulator storage batteries }\left(T_{\text {heater }}=45^{\circ} \mathrm{C}\right)[29] \\
\text { Корпусов электронной аппаратуры } \\
\text { Electronic housings }\left(T_{\text {heater }}=50^{\circ} \mathrm{C}\right)[30] \\
\text { Электронных компонентов серверов и компьютеров } \\
\text { Electronic components of servers and computers }\left(T_{\text {hea- }}\right. \\
\left.\text { ter }=70^{\circ} \mathrm{C}\right)[30] \\
\text { Силовых трансформаторов } \\
\text { Роwer transformers }\left(T_{\text {heater }}=75^{\circ} \mathrm{C}\right)[31] \\
\text { Твердополимерных топливных элементов } \\
\text { Polyethylene fuel cells }\left(T_{\text {heater }}=100^{\circ} \mathrm{C}\right)[32]\end{array}$ \\
\hline $\begin{array}{l}\text { Хими } \\
\text { Chem }\end{array}$ & $\begin{array}{l}\text { Характерные температуры поверхностей химиче- } \\
\text { ских реакторов периодического действия } \\
\text { Typical surface temperatures of batch chemical reactors } \\
\left(T_{\text {heater }}=100^{\circ} \mathrm{C}\right)[33] \\
\end{array}$ \\
\hline $\begin{array}{l}\text { Газовая и } \\
\text { нефтяная } \\
\text { Gas and oil }\end{array}$ & $\begin{array}{l}\text { Максимально допустимые температуры поверхно- } \\
\text { стей подогревателей природного газа } \\
\text { Maximum permissible surface temperatures of natural } \\
\text { gas heaters }\left(T_{\text {heater }}=45^{\circ} \mathrm{C}\right)[34]\end{array}$ \\
\hline
\end{tabular}

Экспериментальное исследование процессов термогравитационной конвекции в горизонтальном слое жидкости малой толщины проведено на стенде (рис. 1) с использованием оборудования теневого метода. 

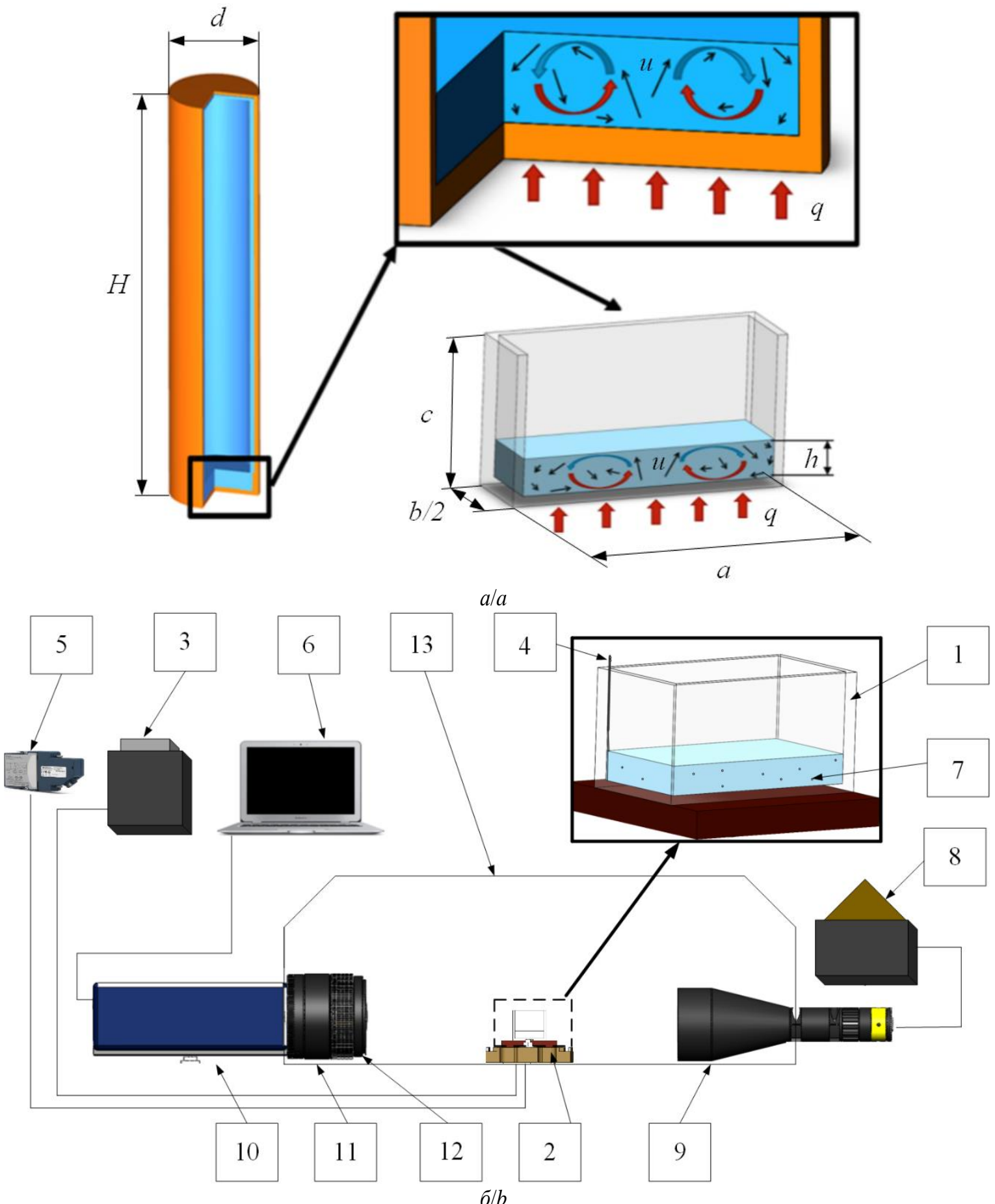

Рис. 1. Схема движения теплоносителя в испарителе термосифона (а) и принципиальная схема экспериментального стенда (б): 1 - кювета с теплоносителем; 2 - нагреватель; 3 - лабораторный автотрансформатор; 4 - термопары; 5 - аналого-иифровой преобразователь National Instruments 9214; 6 - персональный компьютер; 7 - трассеры; 8 -источник света; 9 - телецентрический объектив; 10 - видеокамера; 11 -макрообъектив; 12 - оптический полосовой фильтр; 13 - стеклянный бокс; $h$ - толщина слоя теплоносителя; $q$ плотность теплового потока; и-скорость движения жидкости; $H$, d-высота и диаметр термосифона, соответственно; $a, b, c$-длина, иирина и высота кюветы, соответственно

Fig. 1. Scheme of liquid movement on the thermosyphon lower cover (a) and the schematic diagram of the experimental setup (b): 1 - cuvette with a coolant; 2 - heater; 3 -laboratory autotransformer; 4 -thermocouples; 5 - analog-todigital converter National Instruments 9214; 6 - personal computer; 7 -tracers; 8 - light source; 9 - telecentric lens; 10 - video camera; 11 -macro lens; 12 -optical band pass filter; 13 -glass box; $h$ is the coolant layer thickness; $q$ is the heat flux density; $u$ is the liquid velocity; $H, d$-the height and diameter of the thermosyphon, respectively; $a, b, c$-length, width and height of the cuvette, respectively 


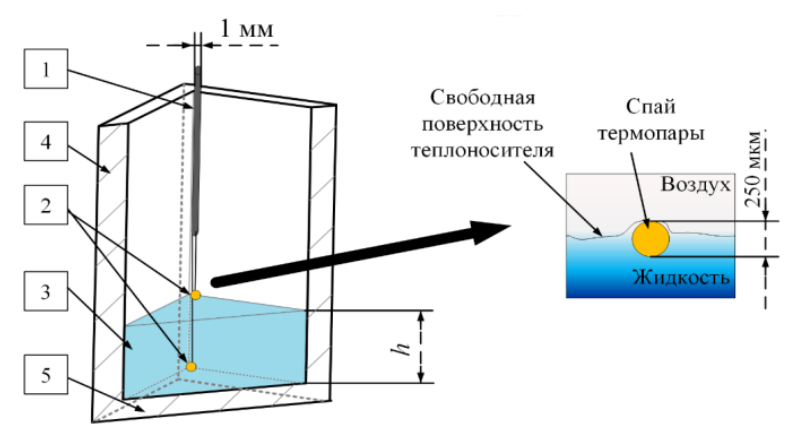

Pис. 2. Схема расположения термопар в слое жидкости: 1 - цилиндр (держатель термопар); 2 термопарыл; 3 - слой жидкости; 4 - вертикальная стенка кюветы; 5 - нижняя крышка кюветы

Fig. 2. Scheme of the thermocouples positioning in the liquid layer: 1 - cylinder (thermocouple adapter); 2 - thermocouples; 3 -liquid layer; 4 -vertical wall of the cuvette; 5 -lower cover of the cuvette

За характерные размеры термосифона [35] (рис. 1,a) приняты $d=42$ мм, $H=161$ мм. Кювета 1 (рис. 1, б), изготовленная в форме прямоугольного параллелепипеда (длиной $a=55$ мм, шириной $b=30$ мм, высотой $c=30$ мм) из кварцевого стекла толщиной 2,5 мм, установлена на нагревателе - 2, который подключен к лабораторному автотрансформатору - 3. На специальном вертикальном цилиндре из оргстекла $(d \approx 1$ мм) (рис. 2) крепились две термопары таким образом, чтобы их спаи находились ниже цилиндра. Расстояние между спаями равнялось толщине слоя жидкости (h). С помощью подвижного механизма цилиндр опускался и термопары погружались в слой жидкости у ребра кюветы на глубину, при которой спай одной термопары регистрировал температуру нижней поверхности слоя жидкости, а спай второй термопары температуру верхней поверхности этого слоя. При этом сам цилиндр находился выше свободной поверхности теплоносителя. При таком положении термопар их влияние на движение жидкости в кювете мало. Температуры нижней поверхности слоя жидкости и вблизи его поверхности испарения регистрировались с помощью термопар в квазистационарном режиме (температура жидкости изменялась не более чем на $0,2{ }^{\circ} \mathrm{C}$ за 10 минут). Размер спая откалиброванных термопар (хромель-алюмель) типа К фирмы OMEGA составлял 250 мкм. Такие размеры спаев применяются при высокоточной регистрации температур капельных жидкостей и газов [36]. Систематическая погрешность измерения температур с помощью термопар составляла $\pm 0,1^{\circ} \mathrm{C}$, случайная погрешность не превышала $6,5 \%$. Показания термопар - 4 (рис. 1, б) с помощью модуля измерения температуры National Instruments 9214 (NI 9214) - 5 передавались на компьютер - 6. Опрос датчика NI 9214 составлял 0,96 секунд.

В жидкость вводились трассеры - частицы оксида железа III $\left(\mathrm{Fe}_{2} \mathrm{O}_{3}\right)-7$ (рис. 1, б), которые не вступают в химические реакции с теплоносителями (вода, этанол) при температурах ниже температуры кипения. Размеры трассеров составляли от 10 до 100 нм, объемная концентрация в жидкости не превышала $2 \%$.
При добавлении трассеров в жидкость происходит их частичная агломерация до размеров $\left(d_{t}\right)$ от 30 до 90 мкм. Аналогично методике [37] определены седиментационные числа для такого диапазона размеров трассеров (от 30 до 90 мкм) и толщин слоя жидкости (от 3,2 до 7,4 мм). Установлено, что даже при толщине слоя жидкости $h=3,2$ мм седиментационные числа $\left(R_{s, c r}\right)$ находились в диапазоне от $455\left(d_{t}=90\right.$ мкм $)$ до $4096\left(d_{t}=30\right.$ мкм), что существенно больше критической величины $R_{s, c r}=157,1$. Следовательно, трассеры оксида железа III размером до 90 мкм не оседают в слоях дистиллированной воды и этанола толщиной до 7,4 мм. По результатам анализа изображений, полученных Particle Tracking Velocimetry (PTV) методом (типичный видеокадр приведен на рис. 3, б), установлено, что во время экспериментов трассеры следовали линиям тока - не осаждались на верхней поверхности нижней крышки кюветы. Через 12 часов после экспериментов трассеры в слое жидкости оставались во взвешенном состоянии и не оседали на верхней поверхности нижней крышки кюветы. Можно утверждать, что трассеры оксида железа III размером до 90 мкм незначительно влияют на процесс термогравитационной конвекции и могут быть использованы при определении скорости движения жидкости. Предполагается, что твердые частицы и жидкость находятся в тепловом равновесии, т. к. теплопроводность трассеров $\left(\mathrm{Fe}_{2} \mathrm{O}_{3}\right)$ много больше теплопроводности воды и этанола и жидкость ведет себя как гомогенная смесь. Поэтому в соответствии с выводами [38] трассеры точно следуют линиям тока несжимаемой жидкости.

Регистрация перемещений трассеров проводилась PTV методом с использованием системы визуализации, включающей галогеновый источник света -8 с телецентрическим объективом - 9 и высокоскоростную видеокамеру - 10 с макрообъективом - 11 и полосовым фильтром - 12 (рис. 1, б). Видеосъемка проводилась с частотой 30 кадров в секунду и разрешением $1280 \times 1024$ пикселя. Область видеофиксации движения трассеров - вертикальное поперечное сечение, проходящее через центр симметрии кюветы. В этом сечении при нагреве нижней крышки кюветы наблюдалась конвективная структура, образующая по центру восходящее и по краям нисходящие течения (рис. $3, a$ ). Прямоугольная форма кюветы выбрана с целью исключения искажения теневых фотоизображений. Искажения не позволили бы с достаточной точностью определить размеры трассеров, их направление и длину пройденного ими пути. Кювета размещалась в стеклянном боксе - 13 с целью уменьшения влияния вынужденной конвекции на проведение эксперимента (рис. 1, б).

На рис. 3 приведена область, в которой проводилось определение скоростей движения жидкости.

Известно [10], что в результате подвода теплоты к нижней крышке кюветы в слое жидкости возникает «стратификация» (изменение по толщине) плотности и температуры, которая генерирует конвективные течения (рис. $3, a$ ), соизмеримые с размерами кюветы. Скорости движения трассеров определялись в цен- 
тральной области, где жидкость перемещалась вверх. Видеокадры, иллюстрирующие перемещение трассе-

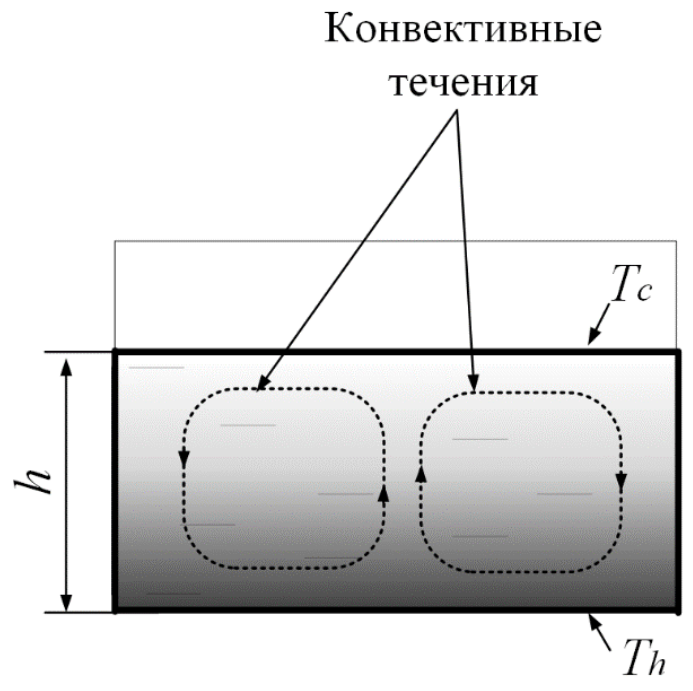

ala ра в слое воды $(h=7,4$ мм) на расстояние $\Delta h$ за 1 секунду при $q \approx 0,2$ кВт/м²

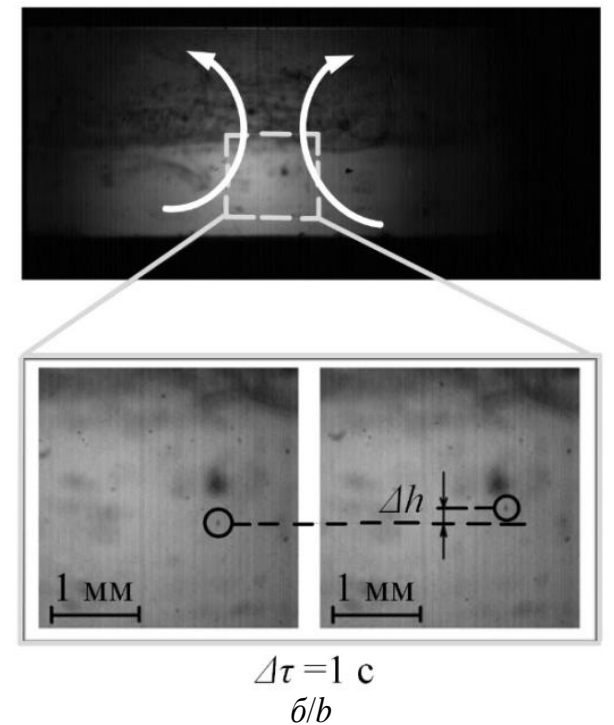

Рис. 3. Область определения скоростей движения жидкости (a): $T_{h}$ и $T_{c}$ - температуры нижней и верхней поверхностей слоя жидкости, соответственно. Видеокадры, иллюстрирующие перемещение трассера в слое воды ( $h=7,4$ мм) на расстояние $\Delta h$ за 1 секунду при $q \approx 0,2 \mathrm{\kappa Bm} / \mathrm{m}^{2}$ (б)

Fig. 3. Region of determination of the liquid movement velocities $(a): T_{h}$ and $T_{c}$ are the temperatures of the lower and upper boundaries of the liquid layer, respectively. Video frames illustrating the movement of the tracer in the water layer $(h=7,4 \mathrm{~mm})$ at a distance of $\Delta h$ in 1 second at $q \approx 0,2 \mathrm{~kW} / \mathrm{m}^{2}(b)$

Локальная скорость движения трассера $\left(u_{t}\right)$ определялась как расстояние $(\Delta h)$, пройденное им за единицу времени. Расстояние измерялось в пикселях. Пересчет расстояния в миллиметры выполнен при использовании масштабного коэффициента $(S \approx 0,015$ мм/пиксель). Скорость движения трассера усреднялась по локальным скоростям $\left(u_{t}\right)$, зарегистрированным в горизонтальных сечениях слоя жидкости с шагом между сечениями 1 мм. За скорость термогравитационной конвекции $\left(u_{\text {conv }}\right)$ принималось среднее арифметическое значение локальных скоростей движения пяти трассеров. Приведенная выше методика определения скоростей движения жидкости не требовала дорогостоящего оборудования как, например, при использовании PIV метода [14], поэтому являлась более простой, но требующей много времени, так как обработка изображений проводилась вручную.

Температура окружающей среды (воздуха) поддерживалась постоянной и соответствовала начальной температуре исследуемой жидкости $T_{a i r}=T_{l .0}=26{ }^{\circ} \mathrm{C}$. В качестве теплоносителя в экспериментах использовались две жидкости: вода и этанол. Обе жидкости достаточно типичны как рабочие в термосифонах. Объем теплоносителя в кювете в квазистационарном режиме составлял 4,$0 ; 6,6 ; 9,2$ мл, что соответствовало толщинам слоя жидкости $(h) 3,2 ; 5,3 ; 7,4$ мм, соответственно. Такая толщина теплоносителя обеспечивает надежную работу систем охлаждения, предотвращая осушение нагретых поверхностей. В экспериментах в условиях нагрева время выхода на квазистационарный режим составляло от 30 минут (при $q \approx 1,3$ кВт/ $\mathrm{m}^{2}$ ) до 80 минут (при $q \approx 0,04$ кВт/м²). За это время в резуль- тате испарения толщина слоя жидкости уменьшалась не более чем на $25 \%$. Поэтому кювета в начале эксперимента заполнялась жидкостью объемом на $30 \%$ больше необходимого.

Потери тепла за счет свободной конвекции от вертикальных стенок кюветы во внешнюю среду определялись по перепаду температур между внешней поверхностью стенки кюветы и окружающим воздухом:

$$
q_{\text {loss }}=\bar{\alpha}\left(T_{w}-T_{\text {air }}\right) .
$$

Коэффициент теплоотдачи в этом случае определялся по выражению [39]:

$$
\bar{\alpha}=\frac{\overline{N u} \lambda_{l}}{H}=\frac{\left(0,825+\frac{0,387 R a^{1 / 6}}{\left(1+\left(\frac{0,492}{\operatorname{Pr}}\right)^{9 / 16}\right)^{8 / 27}}\right)^{2} \lambda_{l}}{H},
$$

где число Рэлея определялось следующим образом [40]:

$$
R a_{H}=\frac{\beta_{\text {air }} \Delta T_{\text {air }} g H^{3}}{v_{\text {air }} a_{\text {air }}},
$$

где $\beta_{\text {air }}$ - коэффициент температурного расширения воздуха, $1 /{ }^{\circ} \mathrm{C} ; \Delta T_{\text {air }}=T_{w}-T_{\text {air }}-$ перепад температуры между внешней стенкой кюветы и окружающим воздухом, ${ }^{\circ} \mathrm{C} ; H$ - высота вертикальных стенок кюветы, м; $v_{\text {air }}$ - коэффициент кинематической вязкости воздуха, м²/c; $a_{\text {air }}$ - коэффициент температуропроводности воздуха, $\mathrm{m}^{2} / \mathrm{c}$. 
По результатам оценки количества тепла $\left(q_{\text {loss }}\right)$, уходящего через вертикальные стенки кюветы, установлено, что потери тепла составляли 53 \%. В экспериментах тепловой поток, передаваемый через слой жидкости, определялся по выражению $q=(U I) / \mathrm{F}-q_{\text {loss }}$ и находился в диапазоне от 0,04 до $1,3 \mathrm{\kappa BT} / \mathrm{m}^{2}$.

Исследования проведены в ламинарном режиме течения. Безразмерный параметр, характеризующий режим течения (число Рэлея), определялся по выражению [40]:

$$
R a_{h}=\frac{\beta_{l} \Delta T_{l} g h^{3}}{v_{l} a_{l}},
$$

где $\beta_{l}-$ коэффициент температурного расширения теплоносителя, $1 /{ }^{\circ} \mathrm{C} ; \Delta T_{l}=T_{h}-T_{c}-$ перепад температуры между нижней и верхней поверхностями слоя теплоносителя, ${ }^{\circ} \mathrm{C} ; v_{l}-$ коэффициент кинематической вязкости жидкости, м ${ }^{2} / \mathrm{c} ; a_{l}-$ коэффициент температуропроводности жидкости, $\mathrm{M}^{2} / \mathrm{c}$.

В проведенных экспериментах $R a=R a_{c}-5 \cdot 10^{5}$ (критическое число Рэлея $R a_{c r} \approx 1100$ [40]). Исключением являлись случаи слоя малой толщины $(h=3,2$ мм) и малого теплового потока $\left(q=0,04\right.$ кВт/м $\left.{ }^{2}\right)$, при котоpых $R a<R a_{c r}$.

B табл. 2 приведены систематические погрешности экспериментов.

Таблица 2. Систематические погрешности экспериментов

Table 2. Systematic errors of experiments

\begin{tabular}{|l|l|c|}
\hline \multicolumn{1}{|l|}{$\begin{array}{l}\text { Параметр } \\
\text { Parameter }\end{array}$} & \multicolumn{1}{|c|}{$\begin{array}{c}\text { Средство измерений } \\
\text { Instrument }\end{array}$} & $\begin{array}{c}\text { Погрешность } \\
\text { Uncertainty }\end{array}$ \\
\hline $\begin{array}{l}\text { Tемпература } \\
\text { Temperature }\end{array}$ & $\begin{array}{l}\text { Термопара } \\
\text { Thermocouple }\end{array}$ & $00,1{ }^{\circ} \mathrm{C}$ \\
\hline $\begin{array}{l}\text { Haпряжение } \\
\text { Voltage }\end{array}$ & $\begin{array}{l}\text { Мультиметр } \\
\text { Multimeter }\end{array}$ & $1,2 \%$ \\
\hline Toк/Current & Мультиметр/Multimeter & $1 \%$ \\
\hline $\begin{array}{l}\text { Объем } \\
\text { Volume }\end{array}$ & $\begin{array}{l}\text { Инсулиновый шприц } \\
\text { Syringe }\end{array}$ & $0,01 \%$ \\
\hline $\begin{array}{l}\text { Toлщина } \\
\text { Thickness }\end{array}$ & $\begin{array}{l}\text { Электронный штангенциркуль } \\
\text { Vernier caliper }\end{array}$ & \\
\hline
\end{tabular}

Случайные погрешности измерений рассчитывались по выражению:

$$
\Delta f=\sqrt{\sum_{i=1}^{n}\left(\frac{\partial f}{\partial x_{i}} \Delta x_{i}\right)^{2}} .
$$

Случайные погрешности определения плотности теплового потока на нижней поверхности крышки кюветы $(q)$, толщины слоя жидкости $(h)$, скорости движения жидкости $\left(u_{t}\right)$, температуры $(T)$ не превышали: $2 ; 6 ; 16 ; 6,5 \%$, соответственно.

\section{Результаты экспериментов и обсуждение}

По результатам серии измерений температур нижней поверхности слоя теплоносителя и его свободной поверхности установлено, что измеренные в углу кюветы температуры не отличались в пределах случайной погрешности измерений от средних по площади нижней и свободной поверхностей слоя жидкости. В табл. 3, 4 приведены средние температуры и пере- пады температуры по толщинам слоев использовавшихся жидкостей.

Таблица 3. Средние температуры и перепады температур в слое воды

Table 3. Average temperatures and temperature differences in water layer

\begin{tabular}{|c|c|c|c|c|}
\hline $\begin{array}{c}h, \\
\mathrm{MM} / \mathrm{mm}\end{array}$ & $\begin{array}{c}q, \\
\mathrm{\kappa BT} / \mathrm{M}^{2} / \mathrm{kW} / \mathrm{m}^{2}\end{array}$ & $T_{h}$ & $T_{c}$ & $\Delta T_{l}=T_{h}-T_{c}$ \\
\cline { 2 - 5 } & 0,04 & 27,6 & 27,0 & \multicolumn{3}{|c|}{$\mathrm{C}$} \\
\hline \multirow{4}{*}{3,2} & 0,18 & 34,9 & 33,5 & 0,6 \\
\cline { 2 - 5 } & 0,43 & 44,0 & 42,2 & 1,4 \\
\cline { 2 - 5 } & 0,79 & 51,5 & 48,0 & 3,5 \\
\cline { 2 - 5 } & 1,27 & 61,6 & 57,4 & 4,2 \\
\hline \multirow{4}{*}{5,3} & 0,04 & 27,9 & 27,5 & 0,4 \\
\cline { 2 - 5 } & 0,18 & 35,3 & 34,1 & 1,2 \\
\cline { 2 - 5 } & 0,43 & 43,8 & 42,0 & 1,8 \\
\cline { 2 - 5 } & 0,79 & 51,9 & 49,2 & 2,7 \\
\hline \multirow{4}{*}{7,4} & 1,27 & 61,6 & 57,7 & 3,9 \\
\cline { 2 - 5 } & 0,04 & 27,7 & 27,3 & 0,4 \\
\cline { 2 - 5 } & 0,18 & 35,6 & 34,5 & 1,0 \\
\cline { 2 - 5 } & 0,43 & 44,4 & 42,8 & 1,6 \\
\cline { 2 - 5 } & 0,79 & 52,5 & 49,8 & 2,7 \\
\hline
\end{tabular}

Таблица 4. Средние температуры и перепады температур в слое этанола

Table 4. Average temperatures and temperature differ-

\begin{tabular}{|c|c|c|c|c|}
\hline \multirow{2}{*}{$\begin{array}{c}h, \\
\mathrm{MM} / \mathrm{mm}\end{array}$} & \multirow{2}{*}{$\begin{array}{c}q, \\
\text { кBT } / \mathrm{M}^{2} / \mathrm{kW} / \mathrm{m}^{2} \\
\end{array}$} & $T_{h}$ & $T_{c}$ & $\Delta T_{l}=T_{h}-T_{c}$ \\
\hline & & \multicolumn{3}{|c|}{${ }^{\circ} \mathrm{C}$} \\
\hline \multirow{5}{*}{3,2} & 0,04 & 27,3 & 26,8 & 0,5 \\
\hline & 0,18 & 34,7 & 33,7 & 1,0 \\
\hline & 0,43 & 45,0 & 43,4 & 1,6 \\
\hline & 0,79 & 56,6 & 54,5 & 2,1 \\
\hline & 1,27 & 67,8 & 64,9 & 2,9 \\
\hline \multirow{5}{*}{5,3} & 0,04 & 27,9 & 27,3 & 0,6 \\
\hline & 0,18 & 35,1 & 33,9 & 1,2 \\
\hline & 0,43 & 45,4 & 43,7 & 1,7 \\
\hline & 0,79 & 56,8 & 54,7 & 2,1 \\
\hline & 1,27 & 69,2 & 66,4 & 2,8 \\
\hline \multirow{5}{*}{7,4} & 0,04 & 29,0 & 28,5 & 0,5 \\
\hline & 0,18 & 34,9 & 34,0 & 0,9 \\
\hline & 0,43 & 45,4 & 43,5 & 1,9 \\
\hline & 0,79 & 57,0 & 53,5 & 3,5 \\
\hline & 1,27 & 67,7 & 62,7 & 5,0 \\
\hline
\end{tabular}
ences in ethanol layer

По результатам анализа экспериментов (табл. 2, 3) установлено, что с ростом толщины слоя воды перепад температуры уменьшается. В слое этанола рост $h$ от 3,2 до 5,3 мм не повлиял на $\Delta T_{l}$. Дальнейший рост $h$ от 5,3 до 7,4 мм привел к увеличению перепада температуры по толщине слоя этанола. Сформулирована гипотеза о том, что с ростом толщины слоя увеличиваются скорости движения жидкости в этом слое и скорость испарения со свободной поверхности. В зависимости от рода жидкости (вода, спирт) эти скорости будут изменятся сильнее или слабее. Полученные результаты (табл. 2, 3) можно объяснить следующим образом. С ростом толщины слоя увеличивались скорости движения жидкости. В результате интенсифицировалось движение охлажденных верхних слоев вниз, нижних более нагретых вверх. В воде такое движение жидкости привело к выравниванию температуры по толщине слоя и, соответственно, 
снижению $\Delta T_{l}$. В этаноле, плотность которого на 25-30 \% меньше, чем у воды, скорости движения жидкости в результате термогравитационной конвекции выше. Последнее приводит как к интенсивному перемешиванию жидкости, так и к большей скорости испарения со свободной поверхности. При испарении этанола его свободная поверхность интенсивно охлаждалась за счет поглощения тепла в результате фазового перехода, что приводило к большим перепадам температуры по толщине слоя жидкости при $h=7,4$ мм по сравнению с $h=3,2-5,4$ мм.

Механизмы конвекции (термогравитационный и термокапиллярный) в подогреваемом снизу слое жидкости со свободной поверхностью действуют одновременно и зависят от толщины $(h)$ этого слоя [41]. При толщине слоя жидкости много больше критической величины $\left(h>>h_{c r}\right)$ определяющую роль в возникновении конвекции играет подъемная сила. Критическая толщина слоя $\left(h_{c r}\right)$ определяется выражением [41]:

$$
h_{c r}=\sqrt{\frac{\sigma_{T}}{\rho_{l} g \Delta T_{l}}},
$$

где $\left(\sigma_{T}=-\partial \sigma \partial T-\right.$ температурный коэффициент поверхностного натяжения, Н/(м·К); $\rho_{l}$ - плотность жидкости, кг $/ \mathrm{M}^{3} ; g$ - ускорение свободного падения, $\mathrm{M} / \mathrm{c}^{2} ; \Delta T_{l}$ - вертикальный градиент температуры в слое жидкости, ${ }^{\circ} \mathrm{C}$.

В проведенных экспериментальных исследованиях отношение толщины слоя жидкости к ее критической величине $\left(h / h_{c r}\right)$ изменялось в диапазоне от 19 до 108 для воды и от 22 до 158 для этанола. Гравитационный параметр $\left(\mu_{T}=v a /\left(g h^{3}\right)\right)$ [42] не превышал 4,2 $10^{-7}$ для воды и $3,7 \cdot 10^{-7}$ для этанола (т. е. $\mu_{T} \longrightarrow 0$ ). По результатам анализа экспериментов $\left(h / h_{c r}\right.$ и $\left.\mu_{T}\right)$ можно сделать вывод, что влияние капиллярных сил на деформацию свободной поверхности мало [42]. Определяющую роль в возникновении конвекции играет термогравитационный механизм (силы плавучести, а не силы поверхностного натяжения). Результаты [43] подтверждают, что механизм, основанный на термокапиллярном эффекте, преобладает при толщинах слоя жидкости менее 2 мм. Поэтому справедливо допущение о пренебрежении термокапиллярной конвекцией, связанной с неоднородностью поверхностного натяжения на свободной поверхности слоя жидкости $(h=3,2-7,4$ мм).

Известно мало результатов экспериментов по определению скоростей (или распределений скоростей) в относительно тонком ( $h=3-9$ мм) слое жидкости (воды или спирта) в условиях нагрева нижней поверхности. Численное решение задачи теплопереноса [13] получено для цилиндра ( $r=3 \mathrm{Mм}, h=7$ мм) с водой. Температура нижней крышки (подложки) поддерживалась постоянной с помощью термостата, а верхняя и боковые стенки исследуемой области были теплоизолированы. При численном моделировании естественной конвекции в цилиндрической области установлено [13] распределение скоростей в центральном полусечении (от оси симметрии до правой границы исследуемой области). Вертикальное распределение скорости на оси симметрии [13] и экспериментальные данные приведены на рис. 4.

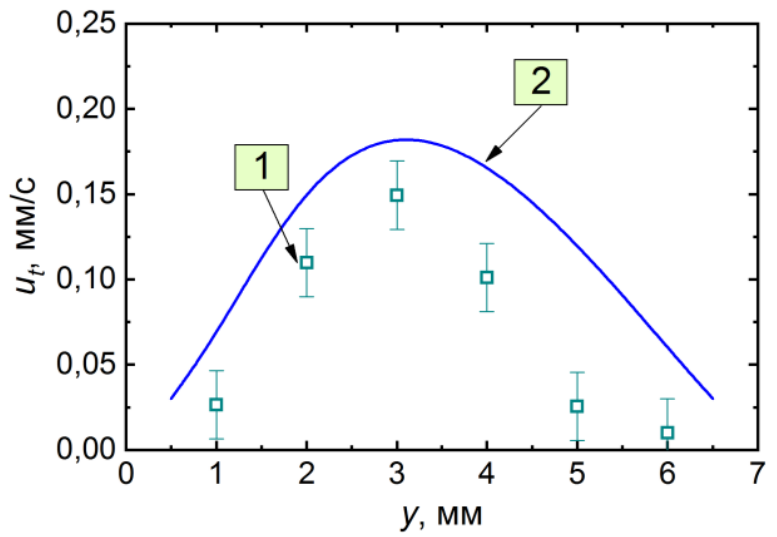

Pис. 4. Распределение скоростей движения жидкости в вертикальном сечении слоя воды:: 1 - экспериментальные данные при $h=7,4 \mathrm{Mм} ; q=0,04 \kappa \mathrm{Bm} / \mathrm{s}^{2}$; $T_{l} \approx 27,5{ }^{\circ} \mathrm{C} ; 2$ - результать численного моделирования [13] при $h=7 \mathrm{Mm}, T_{l} \approx 24{ }^{\circ} \mathrm{C}$

Fig. 4. Distribution of the liquid movement velocities in the water layer vertical section: 1 - experimental data at $h=7,4 \mathrm{~mm} ; q=0,04 \mathrm{~kW} / \mathrm{m}^{2} ; T_{l} \approx 27,5^{\circ} \mathrm{C} ; 2$ - the results of numerical simulation [13] at $h=7 \mathrm{~mm}$, $T_{l} \approx 24^{\circ} \mathrm{C}$

По результатам анализа зависимостей $u_{t}=f(y)$ (рис. 4) установлено, что скорость термогравитационной конвекции в восходящем течении слоя жидкости имеет максимум (минимальные скорости зарегистрированы у нижней и верхней поверхностей слоя теплоносителя). Трассеры ускоренно переносились вверх до середины слоя при подводе теплоты к нижней поверхности слоя теплоносителя, а затем в сечениях выше $h / 2$ они замедляли своё движение. У свободной поверхности трассеры перемещались в горизонтальном направлении к вертикальным стенкам кюветы.

Экспериментальные данные (рис. 4) удовлетворительно соответствуют результатам численного моделирования естественной конвекции [13] в аналогичных условиях. Отличия в скоростях движения воды, установленных в ходе эксперимента, от скоростей, приведенных в [13], вызваны отличием толщины слоя жидкости, его средней температуры и разными условиями на верхней поверхности слоя воды. В [13] верхняя поверхность слоя жидкости была твердой, в проведенных экспериментах верхняя поверхность свободная.

Порядок величин скоростей $\left(10^{-3} \mathrm{M} / \mathrm{c}\right)$ при температурах нижней поверхности слоя жидкости от 27 до $68{ }^{\circ} \mathrm{C}$ совпадает с порядком скоростей течений в каплях воды (0-2,5 мм/с) [44] и слое этанола толщиной 3 мм с потоком газа, движущимся параллельно поверхности раздела «жидкость-газ» (0-4 мм/с) [22]. Зарегистрированные скорости течений в каплях [44] выше, чем в экспериментах, из-за малых размеров капель $(h<1$ мм). Зарегистрированные скорости движения жидкости в слое этанола толщиной 3 мм [22] вы- 
ше, чем в экспериментах, из-за наличия потока газа над свободной поверхностью слоя $\left(U_{g} \geq 13,8 \mathrm{mм} / \mathrm{c}\right)$. Результаты экспериментальных исследований хорошо согласуются с результатами [25], полученными для слоя этанола, испаряющегося в неподвижный воздух с парами спирта. В слое этанола толщиной 3,8 мм [25] средняя скорость течений при $R a=5,71 \cdot 10^{3}$ составляла $0,36 \mathrm{~mm} / \mathrm{c}$. В проведенных экспериментах при тол-
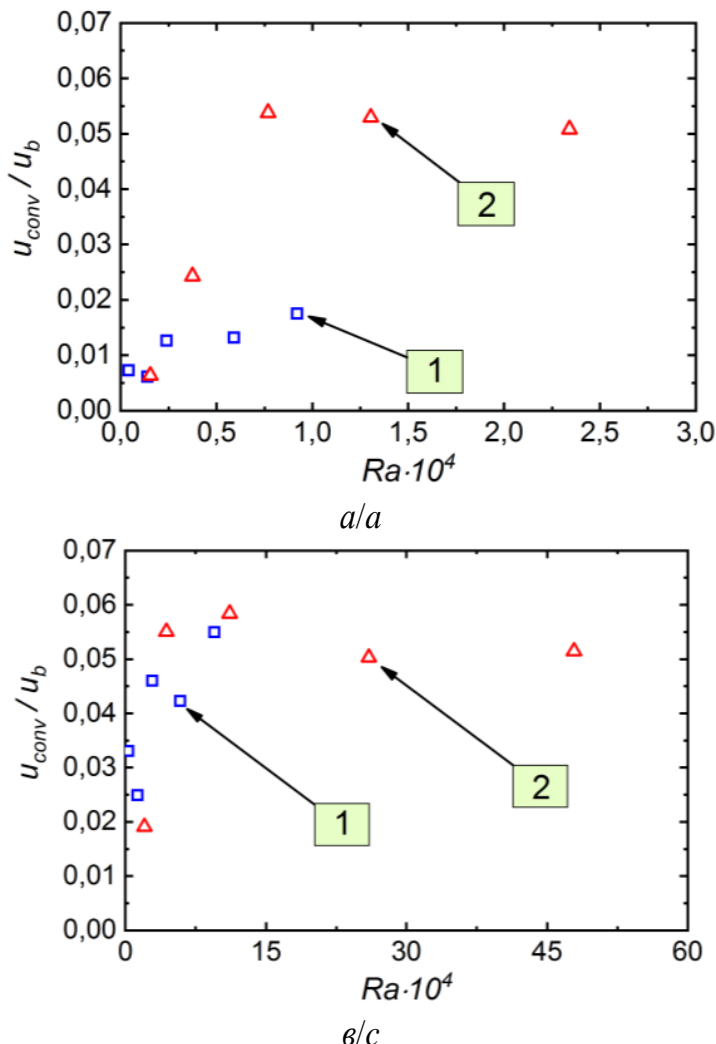

Видно (рис. 5), что с ростом толщины слоя теплоносителя от 3,2 до 7,4 мм безразмерная скорость термогравитационной конвекции изменяется незначительно и находится в диапазоне от 0,005 до 0,06. Скорость движения этанола выше, чем у воды, при числах Рэлея: $R a \approx 2500$ ( $h=3,2$ мм); $R a \approx 9000$ ( $h=5,3$ мм) и $R a \approx 30000$ ( $h=7,4$ мм). щине слоя этанола 3,2 мм и $R a=7,69 \cdot 10^{3}$ составляла $0,42 \mathrm{Mm} / \mathrm{c}$.

По экспериментальным данным $\left(u_{\text {conv }}, \Delta T_{l}\right)$ построены зависимости безразмерной вертикальной скорости (равной отношению скорости термогравитационной конвекции $\left(u_{\text {conv }}\right)$ к скорости плавучести $u_{b}=\sqrt{g \beta_{l} \Delta T_{l} h}$ [22]) от числа Рэлея (рис. 5).

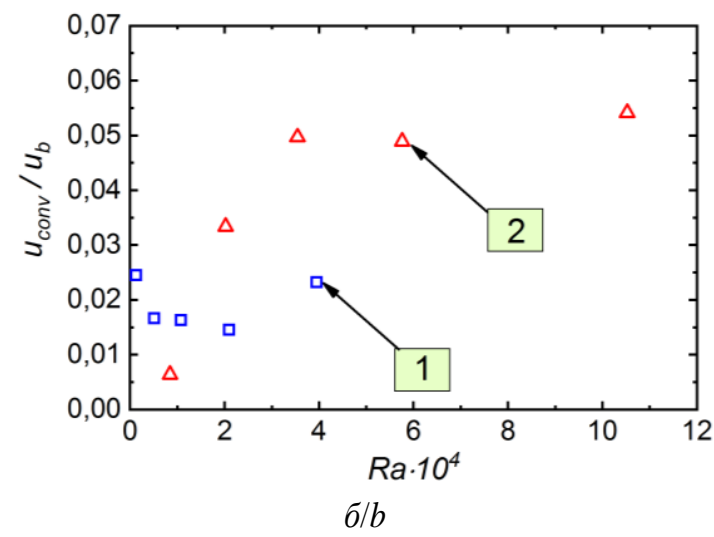

Pис. 5. Зависимости безразмерной вертикальной скорости от числа Рэлея (1 - вода; 2 - этанол) при толщинах слоя жидкости $h: 3,2$ мм (a); 5,3 мм (б); 7,4 мм (в)

Fig. 5. Dependences of the dimensionless velocity on the Rayleigh number (1 - water; 2 - ethanol) at liquid layer thicknesses h: 3,2 $\mathrm{mm}(a) ; 5,3 \mathrm{~mm}(b) ; 7,4 \mathrm{~mm}$ (c)

С целью оценки интенсивности процессов теплопереноса в результате разных механизмов (теплопроводность и конвекция) в слое жидкости ниже приведены зависимости числа Рэлея от плотности теплового потока, подведенного к этому слою (рис. 6).
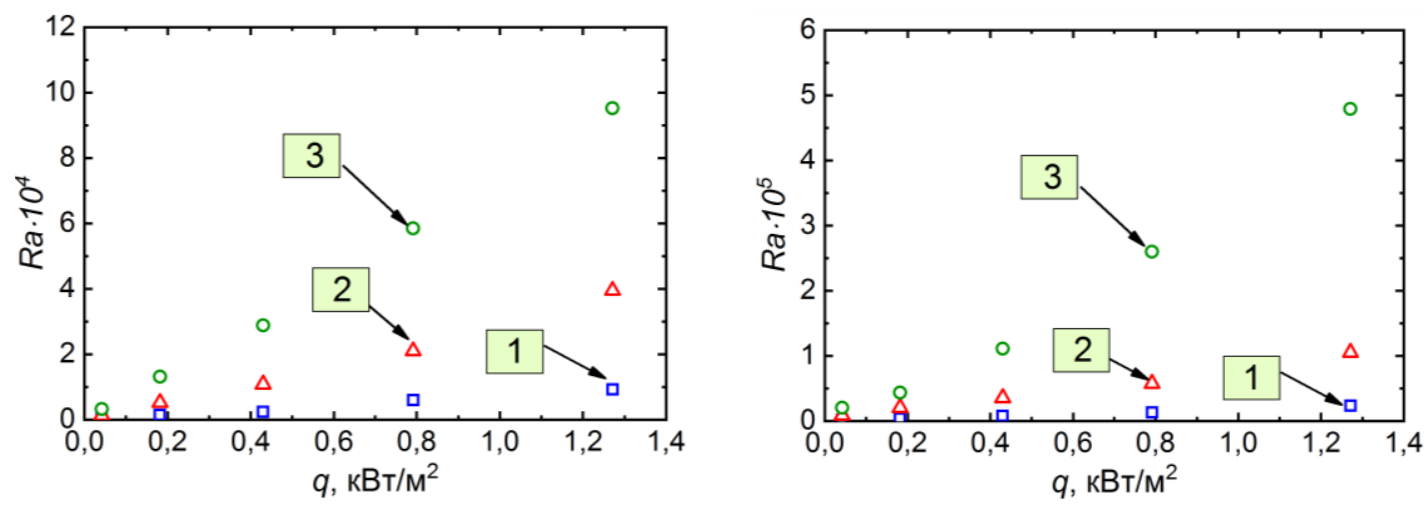

ala

$\sigma / b$

Pис. 6. Зависимости чисел Рэлея от плотности теплового потока, подведенной к слою воды (а) и этанола (б): $1-h=3,2 \mathrm{Mu} ; 2-h=5,3 \mathrm{Mu} ; 3-h=7,4 \mathrm{MM}$

Fig. 6. Dependences of Rayleigh numbers on the heat flux density supplied to the layer of water (a) and ethanol (b): $1-h=3,2 \mathrm{~mm} ; 2-h=5,3 \mathrm{~mm} ; 3-h=7,4 \mathrm{~mm}$ 
Свободная поверхность воды представляет собой крупную ячеистую структуру, которая не движется [45]. В этаноле по сравнению с водой ячейки меньше в несколько раз и свободная поверхность движется за счет термокапиллярного эффекта [45]. Дополнительный вклад эффекта Марангони в процесс конвекции в слое этанола приводит к интенсивному течению в слое по сравнению с водой. Также известно [41], что чем выше число Рэлея, тем интенсивнее происходит процесс конвекции [46]. В экспериментальных исследованиях числа Рэлея в этаноле на порядок превышали $R a$ в воде (рис. 6). Видно (рис. 6), что рост теплового потока и толщины слоя теплоносителя приводит к интенсификации движения жидкости (число Рэлея увеличивается). По результатам анализа зависимостей $R a=f(q)$ можно сделать вывод, что интенсивность процессов теплопереноса в слое этанола выше, чем в воде.

Определено температурное поле в слое жидкости, к нижней поверхности которого подведен тепловой поток $(q)$, а верхняя поверхность охлаждается $\left(\alpha=20 \mathrm{BT} /\left(\mathrm{M}^{2} \cdot{ }^{\circ} \mathrm{C}\right) ; T_{\text {air }}=26{ }^{\circ} \mathrm{C}\right)$. Математическая постановка задачи:

$$
c_{l} \rho_{l} \frac{\partial T}{\partial \tau}=\lambda_{l} \frac{\partial^{2} T}{\partial y^{2}}, \quad 0 \leq y \leq h .
$$

Начальное условие:

$$
T_{\text {init }}=26{ }^{\circ} \mathrm{C}, \tau=0 .
$$

Краевые условия:

$$
\begin{gathered}
-\left.\lambda_{l} \frac{\partial T}{\partial y}\right|_{y=0}=q, \quad \tau>0, \\
-\left.\lambda_{l} \frac{\partial T}{\partial y}\right|_{y=h}=\alpha\left(T_{c}-T_{\text {air }}\right), \quad \tau>0 .
\end{gathered}
$$

Сформулированная задача (1)-(4) теплопроводности в слое жидкости решена методом конечных разностей [9]. Расчеты проводились в диапазоне тепловых потоков $(q)$ от 0,04 до 1,3 кВт/м², толщин $(h)$ слоя жидкости (воды, этанола) от 3,2 до 7,4 мм. Теплофизические свойства теплоносителя принимались при $T_{\text {init }}=26{ }^{\circ} \mathrm{C}[47]$.

Для воды: плотность $\rho_{w}=995 \mathrm{\kappa r} / \mathrm{M}^{3} ;$ теплопроводность $\lambda_{w}=608 \cdot 10^{-3} \mathrm{BT} /(\mathrm{M} \cdot \mathrm{K}) ;$ молярная масса $M_{w}=18 \cdot 10^{-3}$ кг $/$ моль; теплоемкость $C p_{w}=4,184 \cdot 10^{-3}$ Дж/(кг $\left.{ }^{\circ} \mathrm{C}\right)$.

Для этанола: плотность $\rho_{e}=785 \mathrm{\kappa r} / \mathrm{M}^{3} ;$ теплопроводность $\lambda_{e}=168 \cdot 10^{-3} \mathrm{BT} /(\mathrm{м} \cdot \mathrm{K})$; молярная масса $M_{e}=46 \cdot 10^{-3}$ кг/моль; теплоемкость $C p_{e}=2,447 \cdot 10^{-3}$ Дж/(кг $\left.{ }^{\circ} \mathrm{C}\right)$.

На рис. 7 приведены типичные распределения температуры по толщине слоя жидкости при времени 300 c.

Видно (рис. 7), что результаты численного моделирования хорошо согласуются с экспериментальными данными при малом $q=0,04$ кВт/ $\mathrm{M}^{2}$. Чем выше тепловой поток, тем больше расхождение между температурами, полученными численно и экспериментально. Это можно объяснить следующим образом. При постановке математической задачи принято, что теплоперенос в слое жидкости осуществлялся только за счет теплопроводности. Но чем выше q, тем интен- сивнее циркуляционное движение жидкости - перемещение нижних нагретых слоев вверх и верхних, охлажденных за счет фазового перехода (испарения) и теплоотвода во внешнюю среду, вниз. В результате растет температура прилегающих к свободной поверхности слоев жидкости и, соответственно, скорость испарения.
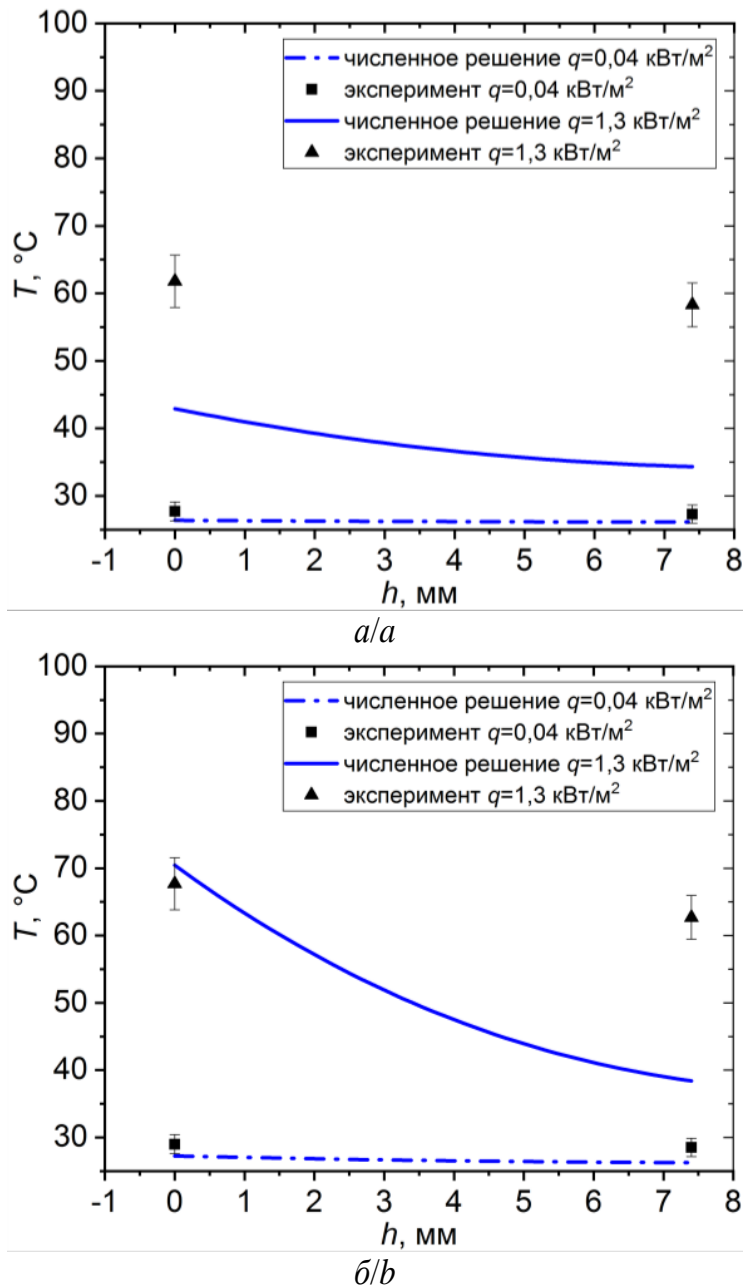

Рис. 7. Распределения температуры по толщине слоя воды (а) и этанола (б) при $\tau=300 \mathrm{c}$

Fig. 7. Temperature distributions over the thickness of water (a) and ethanol (b) layer at $\tau=300 \mathrm{~s}$

\section{Заключение}

По результатам выполненных экспериментальных исследований теплопереноса в малом по толщине слое жидкости в условиях, характерных для нижней крышки термосифона - при нагреве нижней поверхности слоя и испарении его с верхней поверхности, установлены перепады температур по толщине слоя воды и этанола. С ростом толщины слоя воды от 3,2 до 7,4 мм перепад температуры по этому слою уменьшается. В слое этанола, наоборот, увеличивается. Установлено, что с ростом толщины слоя увеличиваются скорости движения жидкости в этом слое и скорость испарения со свободной поверхности. В зависимости от жидкости (вода, спирт) эти скорости будут изменятся сильнее или слабее. Последнее влия- 
ет на перепад температуры по слою и интенсивность теплопереноса в нем.

Установлены числа Рэлея, при которых безразмерная скорость этанола выше, чем у воды. Сделан вывод, что важный вклад в формирование температурного поля слоя теплоносителя в испарителе тер-

\section{СПИСОК ЛИТЕРАТУРЫ}

1. Безродный М.К., Пиоро И.Л., Костюк Т.О. Процессы переноса в двухфазных термосифонных системах. Теория и практика. Киев: Факт, 2005. - 704 с.

2. Переходные процессы в термосифонах / В.А. Мунц, А.И. Папченков, Е.Ю. Павлюк, Д.Р. Даминов // Вестник Южно-Уральского государственного университета. Серия: Энергетика. - 2017. - Т. 17. - № 4. - С. 5-13.

3. Effect of sintered microporous coating at the evaporator on the thermal performance of a two-phase closed thermosyphon / Y. Kim, D.H. Shin, J.S. Kim, S.M. You, J. Lee // International Journal of Heat and Mass Transfer. - 2019. - V. 131. - P. 1064-1074.

4. Boiling and condensation heat transfer of inclined two-phase closed thermosyphon with various filling ratios / Y Kim, D.H. Shin, J.S. Kim, S.M. You, J. Lee // Applied Thermal Engineering. - 2018. - V. 145 - P. 328-342.

5. Performance optimization of a two-phase closed thermosyphon through CFD numerical simulations / S. Fertahi, T. Bouhal, Y. Agrouaz, T. Kousksou, T. El Rhafiki, Y. Zeraouli // Applied Thermal Engineering. - 2018. - V. 128. - P. 551-563.

6. Alizadehdakhel A., Rahimi M., Alsairafi A.A. CFD modeling of flow and heat transfer in a thermosyphon // International Communications in Heat and Mass Transfer. - 2010. - V. 37. - Iss. 3. P. 312-318

7. Kuznetsov G.V., Sitnikov A.E. Numerical analysis of basic regularities of heat and mass transfer in a high-temperature heat pipe // High temperature. - 2002. - V. 40. - Iss. 6. - P. 964-970.

8. Ponomarev K., Feoktistov D., Abedtazehabadi A. Experimental investigation of the heat transfer intensity in thermosyphon // AIP Conference Proceedings. - 2019. - V. 2135. - Iss. 1. - P. 020048.

9. Максимов В.И., Нурпейис А.Е. Новый подход к моделированию процесса формирования теплового режима термосифонов больших размеров для использования геотермальной теплоты // Известия Томского политехнического университета. Инжиниринг георесурсов. - 2019. - Т. 330. - № 8. - С. 78-86.

10. Polezhaev V.I., Myakshina M.N., Nikitin S.A. Heat transfer due to buoyancy-driven convective interaction in enclosures: Fundamentals and applications // International Journal of Heat and Mass Transfer. - 2012. - V. 55. - Iss. 1-3. - P. 156-165.

11. Novev J.K., Compton R.G. Natural convection effects in electrochemical systems // Current Opinion in Electrochemistry. - 2018. V. 7. - P. 118-129

12. Thermocapillary flow transition in an evaporating liquid layer in a heated cylindrical cell / W. Liu, P.G. Chen, J. Ouazzani, Q. Liu // International Journal of Heat and Mass Transfer. - 2020. V. 153. - Iss. 119587. - P. 1-10.

13. Novev J.K., Compton R.G. Thermal convection in electrochemica cells. Boundaries with heterogeneous thermal conductivity and implications for scanning electrochemical microscopy // Physical Chemistry Chemical Physics. - 2017. - V. 19. - Iss. 20. P. 12759-12775.

14. Lyulin Y.V., Kreta A.S., Kabov O.A. Effect of gas flow velocity on convection in a horizontal evaporating liquid layer // Thermophysics and Aeromechanics. - 2019. - V. 26. - Iss. 1. P. $133-138$

15. Onset of thermal ripples at the interface of an evaporating liquid under a flow of inert gas / B. Scheid, J. Margerit, C.S. Iorio, L. Joannes, M. Heraud, P. Queeckers, P.C. Dauby, P. Colinet // Experiments in fluids. - 2012. - V. 52. - Iss. 5. - P. 1107-1119.

16. A vision-based Particle Tracking Velocimetry / A. Baldassarre, M. De Lucia, P. Nesi, F. Rossi // Real-Time Imaging. - 2001. V. 7. - Iss. 2. - P. 145-158.

17. Волков Р.С., Войтков И.С., Высокоморная О.В. Особенности тушения жидких топлив и органических горючих жидкостей распыленным потоком воды // Пожаровзрывобезопасность. 2016. - Т. 25. - № 4. - С. 68-75. мосифона вносит термогравитационная конвекция и ее необходимо учитывать, даже в относительно простых моделях.

Исследование выполнено при финансовой поддержке РФФИ в рамках научного проекта № 19-38-90137.

18. The influence of key parameters on combustion of double gas hydrate / S.Y. Misyura, A.Y. Manakov, V.S. Morozov, G.S. Nyashina, O.S. Gaidukova, S.S. Skiba, R.S. Volkov, I.S. Voytkov // Journal of Natural Gas Science and Engineering. 2020. - V. 80. - P. 103396.

19. Iorio C.S., Kabov O.A., Legros J.C. Thermal patterns in evaporating liquid // Microgravity Science and Technology. - 2007. V. 19. - Iss. 3/4. - P. 27-29.

20. Sllveston P.L. Wärmedurchgang in waagerechten Flüssigkeitsschichten // Forschung auf dem Gebiet des Ingenieurwesens A. 1958. - V. 24. - Iss. 2. - P. 59-69.

21. Lewandowski W.M., Kubski P. Methodical investigation of free convection from vertical and horizontal plates // Wärme - und Stoffübertragung. - 1983. - V. 17. - Iss. 3. - P. 147-154.

22. Experimental study of the convective motions by the PIV technique within an evaporating liquid layer into the gas flow / Y. Lyulin, A. Kreta, H. Ouerdane, O. Kabov // Microgravity Science and Technology. - 2020. - V. 32. - Iss. 2. - P. 203-216.

23. Влияние нестационарной тепловой гравитационнокапиллярной конвекции на распределение температуры в тонкой вертикальной стенке / В.С. Бердников, В.А. Гапонов, В.А. Гришков, П.М. Лиханский, В.А. Марков // Теплофизика и аэромеханика. - 2010. - Т. 17. - № 2. - С. 197-208.

24. Бердников В.С., Митин К.А., Кислицын С.А. Влияние нестационарной гравитационно-капиллярной конвекции на поля температуры в тонкой стенке // Научный вестник Новосибирского государственного технического университета. - 2014. № 4. - C. 131-146.

25. Тепловизионные исследования ламинарно-турбулентного перехода в рэлей-бенаровской конвекции / В.С. Бердников, В.А. Гришков, К.Ю. Ковалевский, В.А. Марков // Автометрия. - 2012. - Т. 48. - № 3. - С. 111-120.

26. Two-phase thermosyphon loop for cooling outdoor telecommunication equipments / A. Samba, H. Louahlia-Gualous, S. Le Masson, D. Nörterhäuser // Applied Thermal Engineering. - 2013. V. 50. - Iss. 1. - P. 1351-1360.

27. Самойлов А.Г., Волков В.С. Тепловыделяющие элементы ядерных реакторов // Атомная энергия. - 1959. - Т. 6. - № 3. - С. 261-276.

28. Белянский Д.А., Игонин В.И., Синицын А.А. Разработка энергосберегающей системы контроля и оценки теплосодержания футервоки промежуточного ковша на участке разогрева стали // Тезисы докладов и сообщений XV Минского международного форума по тепло- и массообмену: в 3 т. - Минск. - 2016. T. 3. - C. 109-111.

29. Multi-objective optimization design of double-layered reverting cooling plate for lithium-ion batteries / T. Deng, Y. Ran, Y. Yin, X. Chen, P. Liu // International Journal of Heat and Mass Transfer. - 2019. - V. 143. - P. 118580.

30. Хайрнасов С.М. Применение тепловых труб в системах обеспечения тепловых режимов РЭА: современное состояние и перспективы // Технология и конструирование в электронной аппаратуре. - 2015. - № 2/3. - С. 19-33.

31. Завидей В.И., Печенкин В.И., Каланчин С.В. Возможности применения тепловизионного контроля для диагностики технического состояния силовых трансформаторов // Энергоэксперт. - 2011. - № 6. - C. 64-67.

32. Kim Y.S., Pivovar B.S. Polymer electrolyte membranes for direct methanol fuel cells // Advances in fuel cells. - 2007. - V. 1. P. 187-234.

33. Тюрин Ю.Н. Особенности расчета поверхности теплопередачи реактора периодического действия // Вестник Кузбасского государственного технического университета. - 2008. - № 3. C. $98-101$.

34. Современное оборудование для газораспределительных станций. Подогреватель газа с промежуточным теплоносителем ПГПТ-3 // Сфера нефтегаз. - 2010. - № 3. - С. 48-49. 
35. Ponomarev K., Feoktistov D., Abedtazehabadi A. Aspects of the research methodology of convection, conduction, evaporation and condensation jointly occurring in the thermosyphon. AIP Conference Proceedings. - 2019. - V. 2135. - Iss. 1. - P. 020047.

36. Shankar P.N., Deshpande M.D. On the temperature distribution in liquid-vapor phase change between plane liquid surfaces // Physics of Fluids A: Fluid Dynamics. - 1990. - V. 2. - Iss. 6. P. 1030-1038.

37. Трубицын В.П. Гравитационная дифференциация в режимах от стоксового осаждения до струй Рэлея-Тейлора // Физика Земли. - 2019. - № 2. - С. 15-30.

38. Abouali O., Ahmadi G. Computer simulations of natural convection of single phase nanofluids in simple enclosures: a critical review // Applied Thermal Engineering. - 2012. - V. 36. - P. 1-13.

39. Churchill S.W., Chu H.H.S. Correlating equations for laminar and turbulent free convection from a vertical plate // International Journal of Heat and Mass Transfer. - 1975. - V. 18. - Iss. 11. P. 1323-1329.

40. Chandrasekhar S. Hydrodynamic and hydromagnetic stability. New York: Dover Publications Inc, 1981. - 704 p.

41. Гарифуллин Ф. А. Возникновение конвекции в горизонтальных слоях жидкости // Соросовский образовательный журнал. - 2000. - Т. 6. - № 8. - С. 108-114.
42. Гершуни Г.3., Жуховицкий Е.М. Конвективная устойчивость несжимаемой жидкости. - М.: Наука, 1972. - 392 с.

43. Эйдельман Е.Д. Конвективные ячейки: три приближения теории опытов Бенара // Соросовский образовательный журнал. 2000. - T. 6. - № 5. - C. 94-100.

44. The role of convection in gas and liquid phases at droplet evaporation / P.A. Strizhak, R.S. Volkov, S.Y. Misyura, S.I. Lezhnin, V.S. Morozov // International Journal of Thermal Sciences. 2018. - V. 134. - P. 421-439.

45. Возникновение конвекции в приповерхностном слое жидкости / Ю.Ю. Плаксина, Ю.К. Руденко, А.В. Пуштаев, Н.А. Винниченко, А.В. Уваров // Процессы в геосредах. 2017. - № 3. - C. 618-625.

46. Liu B., Zhang J. Self-induced cyclic reorganization of free bodies through thermal convection // Physical review letters. - 2008. V. 100. - Iss. 24. - P. 244501.

47. New cooling approach using successive evaporation and condensation of a liquid film inside a vertical mini-channel / M. Najim, M. Feddaoui, N.A. Alla, A. Charef, A.E. Kabeel // International Journal of Heat and Mass Transfer. - 2018. - V. 122. - P. 895-912.

Поступила 01.03.2021 2.

\section{Информация для авторов}

Феоктистов Д.В., кандидат технических наук, доцент Исследовательской школы физики высокоэнергетических процессов Национального исследовательского Томского политехнического университета.

Пономарев К.О., аспирант Инженерной школы энергетики Национального исследовательского Томского политехнического университета. 
UDC 536.24

\title{
HEAT TRANSFER IN A THIN LIQUID LAYER UNDER CONDITIONS CHARACTERISTIC FOR THE LOWER COVER OF A THERMOSYPHON
}

\author{
Dmitry V. Feoktistov' \\ fdv@tpu.ru
}

\author{
Konstantin O. Ponomarev1, \\ kop.tpu@gmail.com \\ 1 National Research Tomsk Polytechnic University, \\ 30, Lenin avenue, Tomsk, 634050, Russia.
}

\begin{abstract}
The relevance. It is impossible to create new technologies for utilizing the heat of flue gases generated in various metallurgical processes and during the combustion of organic fuels in thermal power plants without the development of fundamental knowledge of heat transfer in energy-efficient, reliable thermodynamic systems based on thermosyphons. The relevance of the heat transfer study in a relatively thin liquid layer (no more than $10 \mathrm{~mm}$ ) in a thermosyphon evaporator is justified by the necessity to develop mathematical models. These models are simpler than the ones based on Navier-Stokes equations or taking into account only the heat conduction mechanism.

The purpose is to evaluate the contribution of thermogravitational convection to the heat transfer in a thin liquid layer under conditions characteristic of the thermosyphon lower cover, when the layer lower boundary is heated and there is evaporation from the upper boundary. Objects: liquid layer on the thermosyphon lower cover.

Methods. The tracers trajectories in the liquid layer were determined using the shadow method. Tracer displacements were recorded using the Particle Tracking Velocimetry method using a special visualization system. The problem of thermal conductivity in a liquid layer is solved by the finite difference method.

Results. Based on the experimental studies of heat transfer in a thin liquid layer, the effect of the heat flux density, the liquid layer thickness, and the properties of the coolant on the temperatures and velocities in this layer has been established. The conditions corresponded in terms of the main significant factors to the heating of the coolant on the thermosyphon lower cover. The increase in the heat flow and the coolant layer thickness was found to lead to intensification of circulation flows. It was shown that in the laminar flow regime $\left(R a=10^{3}-5 \cdot 10^{5}\right)$, the heat transfer intensity in the ethanol layer was higher than that of water. In addition, in a thin liquid layer (from 3,2 to 7,4 mm), the thermogravitational convection was much more intense than heat conduction.
\end{abstract}

\section{Key words:}

Thermosyphon, liquid layer, thermogravitational convection, experiment, liquid velocity, heat flux.

The reported study was funded by RFBR, project number 19-38-90137.

\section{REFERENCES}

1. Bezrodny M.K., Pioro I.L., Kostyuk T.O. Protsessy perenosa v dvukhfaznykh termosifonnykh sistemakh. Teoriya $i$ praktika [Transfer processes in two-phase thermosyphon systems. Theory and practice]. Kiev, Fakt Publ., 2005. 704 p.

2. Munts V.A., Papchenkov A.I., Pavlyuk E.Yu., Daminov D.R. Transient processes at thermosyphons. Bulletin of the South Ural State University. Series: Energy, 2017, vol. 17, no. 4, pp. 5-13. In Rus

3. Kim Y., Shin D.H., Kim J.S., You S.M., Lee J. Effect of sintered microporous coating at the evaporator on the thermal performance of a two-phase closed thermosyphon. International Journal of Heat and Mass Transfer, 2019, vol. 131, pp. 1064-1074.

4. Kim Y., Shin D.H., Kim J.S., You S.M., Lee J. Boiling and condensation heat transfer of inclined two-phase closed thermosyphon with various filling ratios. Applied Thermal Engineering, 2018, vol. 145, pp. 328-342.

5. Fertahi S., Bouhal T., Agrouaz Y., Kousksou T., Rhafiki T. El, Zeraouli Y. Performance optimization of a two-phase closed thermosyphon through CFD numerical simulations. Applied Thermal Engineering, 2018, vol. 128, pp. 551-563.

6. Alizadehdakhel A., Rahimi M., Alsairafi A.A. CFD modeling of flow and heat transfer in a thermosyphon. International Communications in Heat and Mass Transfer, 2010, vol. 37, no. 3, pp. 312-318.

7. Kuznetsov G.V., Sitnikov A.E. Numerical analysis of basic regularities of heat and mass transfer in a high-temperature heat pipe. High temperature, 2002, vol. 40, no. 6, pp. 964-970

8. Ponomarev K., Feoktistov D., Abedtazehabadi A. Experimental investigation of the heat transfer intensity in thermosyphon. AIP Conference Proceedings, 2019, vol. 2135, no. 1, p. 020048.

9. Maksimov V.I., Nurpeiis A.E. New approach to modelling the formation of large sized thermosiphons thermal regime for using geothermal heat. Bulletin of the Tomsk Polytechnic University. Geo Assets Engineering, 2019, vol. 330, no. 8, pp. 78-86. In Rus.

10. Polezhaev V.I., Myakshina M.N., Nikitin S.A. Heat transfer due to buoyancy-driven convective interaction in enclosures: Fundamentals and applications. International Journal of Heat and Mass Transfer, 2012, vol. 55, no. 1-3, pp. 156-165.

11. Novev J.K., Compton R.G. Natural convection effects in electrochemical systems. Current Opinion in Electrochemistry, 2018, vol. 7, pp. 118-129.

12. Liu W., Chen P.G., Ouazzani J., Liu Q. Thermocapillary flow transition in an evaporating liquid layer in a heated cylindrical cell. International Journal of Heat and Mass Transfer, 2020, vol. 153, no. 119587, pp. 1-10.

13. Novev J.K., Compton R.G. Thermal convection in electrochemical cells. Boundaries with heterogeneous thermal conductivity and implications for scanning electrochemical microscopy. Physical Chemistry Chemical Physics, 2017, vol. 19, no. 20, pp. 12759-12775.

14. Lyulin Y.V., Kreta A.S., Kabov O.A. Effect of gas flow velocity on convection in a horizontal evaporating liquid layer. Thermophysics and Aeromechanics, 2019, vol. 26, no. 1, pp. 133-138.

15. Scheid B., Margerit J., Iorio C.S., Joannes L., Heraud M., Queeckers P., Dauby P.C., Colinet P. Onset of thermal ripples at the interface of an evaporating liquid under a flow of inert gas. Experiments in fluids, 2012, vol. 52, no. 5, pp. 1107-1119.

16. Baldassarre A., De Lucia M., Nesi P., Rossi F. A vision-based Particle Tracking Velocimetry. Real-Time Imaging, 2001, vol. 7, no. 2, pp. $145-158$.

17. Volkov R.S., Voytkov I.S., Vysokomornaya O.V. Features of extinguishing of the liquid fuels and organic flammable liquids by an atomized water flow. Fire and Explosion Safety, 2016, vol. 25, no. 4, pp. 68-75. In Rus. 
18. Misyura S.Y., Manakov A.Y., Morozov V.S., Nyashina G.S., Gaidukova O.S., Skiba S.S., Volkov R.S., Voytkov I.S. The influence of key parameters on combustion of double gas hydrate. Journal of Natural Gas Science and Engineering, 2020, vol. 80, p. 103396.

19. Iorio C.S., Kabov O.A., Legros J.C. Thermal patterns in evaporating liquid. Microgravity Science and Technology, 2007, vol. 19, no. 3/4, pp. 27-29.

20. Sllveston P.L. Wärmedurchgang in waagerechten Flüssigkeitsschichten [Heat transfer in horizontal liquid layers]. Forschung auf dem Gebiet des Ingenieurwesens A, 1958, vol. 24, no. 2, pp. 59-69.

21. Lewandowski W.M., Kubski P. Methodical investigation of free convection from vertical and horizontal plates. Wärme - und Stoffübertragung, 1983, vol. 17, no. 3, pp. 147-154. In Germ.

22. Lyulin Y., Kreta A., Ouerdane H., Kabov O. Experimental study of the convective motions by the PIV technique within an evaporating liquid layer into the gas flow. Microgravity Science and Technology, 2020, vol. 32, no. 2, pp. 203-216.

23. Berdnikov V.S., Gaponov V.A., Grishkov V.A., Likhansky P.M., Markov V.A. Effect of nonstationary thermal gravitation-capillary convection on temperature distribution in a thin vertical wall. Thermophysics and Aeromechanics, 2010, vol. 17, no. 2, pp. 181-191.

24. Berdnikov V.S., Mitin K.A., Kislitsyn S.A. Influence of nonstationary thermal-capillary and gravitational convection on temperature fields in a thin wall. Scientific Bulletin of Novosibirsk State Technical University, 2014, no. 4, pp. 131-146. In Rus.

25. Berdnikov V.S., Grishkov V.A., Kovalevskii K.Yu., Markov V.A Teplovizionnye issledovaniya laminarno-turbulentnogo perekhoda $\mathrm{v}$ reley-benarovskoy konvektsii [Thermal imaging studies of laminar-turbulent transition in Rayleigh-Benard convection]. Avtometriya, 2012, vol. 48, no. 3, pp. 111-120.

26. Samba A., Louahlia-Gualous H., Le Masson S., Nörterhäuser D. Two-phase thermosyphon loop for cooling outdoor telecommunication equipments. Applied Thermal Engineering, 2013, vol. 5, no. 1 , pp. $1351-1360$

27. Samoylov A.G., Volkov V.S. Teplovydelyayushchie elementy yadernykh reaktorov [Fuel elements of nuclear reactors]. Atomnaya energiva, 1959 , vol. 6 , no. 3, pp. 261-276.

28. Belyanskiy D.A., Igonin V.I., Sinitsyn A.A. Razrabotka energosberegayushchey sistemy kontrolya $\mathrm{i}$ otsenki teplosoderzhaniya futervoki promezhutochnogo kovsha na uchastke razogreva stal [Development of an energy-saving system for monitoring and evaluating the heat content of the tundish liner at the steel heating section]. Tezisy dokladov i soobshcheniy XV Minskogo mezhdunarodnogo foruma po teplo- $i$ massoobmenu $[\mathrm{XV}$ Minsk International Forum on Heat and Mass Transfer. Abstracts of reports and messages]. Minsk, 2016. Vol. 3, pp. 109-111.

29. Deng T., Ran Y., Yin Y., Chen X., Liu P. Multi-objective optimization design of double-layered reverting cooling plate for lithiumion batteries. International Journal of Heat and Mass Transfer, 2019 , vol. 143 , p. 118580.

30. Khairnasov S.M. The use of heat pipes in thermal control system for electronics: current situation and prospects. Technology and design in electronic equipment, 2015, no. 2/3, pp. 19-33. In Rus.

31. Zavidey V.I., Pechenkin V.I., Kalanchin S.V. Vozmozhnosti primeneniya teplovizionnogo kontrolya dlya diagnostiki tekhnicheskogo sostoyaniya silovykh transformatorov [Possibilities of using thermal imaging control for diagnostics of the technical condition of power transformers]. Energoekspert, 2011, no. 6, pp. 64-67.
32. Kim Y.S., Pivovar B.S. Polymer electrolyte membranes for direct methanol fuel cells. Advances in fuel cells, 2007, vol. 1, pp. 187-234.

33. Tyurin Yu.N. Osobennosti rascheta poverkhnosti teploperedachi reaktora periodicheskogo deystviya [Features of calculating the heat transfer surface of a batch reactor]. Vestnik Kuzbasskogo gosudarstvennogo tekhnicheskogo universiteta, 2008, no. 3, pp. $98-101$.

34. Sovremennoe oborudovanie dlya gazoraspredelitelnykh stantsiy. Podogrevatel gaza s promezhutochnym teplonositelem PGPT-3 [Modern equipment for gas distribution stations. Gas heater with intermediate heat carrier PGPT-3. Sfera neftegaz, 2010, no. 3, pp. $48-49$.

35. Ponomarev K., Feoktistov D., Abedtazehabadi A. Aspects of the research methodology of convection, conduction, evaporation and condensation jointly occurring in the thermosyphon. AIP Conference Proceedings, 2019, vol. 2135, no. 1, p. 020047.

36. Shankar P.N., Deshpande M.D. On the temperature distribution in liquid-vapor phase change between plane liquid surfaces. Physics of Fluids A: Fluid Dynamics, 1990, vol. 2, no. 6, pp. 1030-1038.

37. Trubitsyn V.P. Gravitational differentiation in the regimes from stokes settling to Rayleigh-Taylor flows. Izvestiya, Physics of the Solid Earth, 2019, no. 2, pp. 15-30. In Rus.

38. Abouali O., Ahmadi G. Computer simulations of natural convection of single phase nanofluids in simple enclosures: a critical review. Applied Thermal Engineering, 2012, vol. 36, pp. 1-13.

39. Churchill S.W., Chu H.H.S. Correlating equations for laminar and turbulent free convection from a vertical plate. International Journal of Heat and Mass Transfer, 1975, vol. 18, no. 11, pp. 1323-1329.

40. Chandrasekhar S. Hydrodynamic and hydromagnetic stability. New York, Dover Publications Inc, 1981, $704 \mathrm{p}$

41. Garifullin F.A. Vozniknovenie konvektsii v gorizontalnykh sloyakh zhidkosti [The occurrence of convection in horizontal layers of liquid]. Sorosovskiy obrazovatelny zhurnal, 2000, vol. 6, no. 8, pp. 108-114.

42. Gershuni G.Z., Zhuhovitskiy E.M. Konvektivnaya ustoychivost neszhimaemoy zhidkosti [Convective stability of an incompressible fluid]. Moscow, Nauka Publ., 1972. 392 p.

43. Eydelman E.D. Konvektivnye yacheyki: tri priblizheniya teorii opytov Benara [Convective cells: three approximations of Benard's theory of experiments]. Sorosovskiy obrazovatelny zhurnal, 2000, vol. 6, no. 5, pp. $94-100$.

44. Strizhak P.A., Volkov R.S., Misyura S.Y., Lezhnin S.I., Morozov V.S. The role of convection in gas and liquid phases at droplet evaporation. International Journal of Thermal Sciences, 2018, vol. 134, pp. 421-439.

45. Plaksina Yu.Yu., Rudenko Yu.K., Pushtaev A.V., Vinnichenko N.A., Uvarov A.V. Onset of convection in near-surface layer of the liquid. Processes in geomedia, 2017, no. 3, no. 5, pp. 618-625. In Rus.

46. Liu B., Zhang J. Self-induced cyclic reorganization of free bodies through thermal convection. Physical review letters, 2008, vol. 100 , no. 24 , p. 244501

47. Najim M., Feddaoui M., Nait Alla A., Charef A., Kabeel A.E. New cooling approach using successive evaporation and condensation of a liquid film inside a vertical mini-channel. International Journal of Heat and Mass Transfer, 2018, vol. 122, pp. 895-912.

Received: 1 March 2021.

\section{Information about the authors}

Dmitry V. Feoktistov, Cand. Sc., associate professor, National Research Tomsk Polytechnic University. Konstantin O. Ponomarev, postgraduate student, National Research Tomsk Polytechnic University. 